\title{
The neural substrates of script knowledge deficits as revealed by a PET study in Huntington's
}

\section{disease}

Philippe Allain $^{\mathrm{a}, \mathrm{b}, \mathrm{c}, *}$, Véronique Gaura ${ }^{\mathrm{d}, \mathrm{e}}$, Luciano Fasotti ${ }^{\mathrm{f}, \mathrm{g}}$, Valérie Chauvirée ${ }^{\mathrm{a}, \mathrm{b}}$, Adriana, Prundean ${ }^{\mathrm{a}}$, Clarisse Sherer-Gagou ${ }^{\mathrm{a}}$, Dominique Bonneau ${ }^{\mathrm{h}}$, Anne-Catherine Bachoud-Levi ${ }^{\mathrm{i}, \mathrm{j}, \mathrm{k}, \mathrm{l}}$

Frédéric Dubas $^{\mathrm{a}, \mathrm{b}}$, Philippe Remy ${ }^{\mathrm{d}, \mathrm{e}, \mathrm{k}, \mathrm{m}}$, Didier Le Gall, ${ }^{\mathrm{a}, \mathrm{b}, \mathrm{c}}$ and Christophe Verny ${ }^{\mathrm{a}}$

a Département de Neurologie, CHU Angers, France

bentre Mémoire de Ressources et de Recherche, CHU Angers, France

cLaboratoire de Psychologie (UPRES EA 2646), Université d’Angers, France

'URA CEA-CNRS 2210, Orsay, France

${ }^{\mathrm{e}}$ CEA Service hospitalier Frédéric Joliot, DRM, Orsay, France

${ }^{\mathrm{f}}$ Sint Maartenskliniek Research, Development and Education, Nimègue, Hollande

${ }^{g}$ Radboud University Nijmegen, Donders Institute for Brain, Cognition and Behaviour, Nimègue,

Hollande

h Département de Génétique, CHU Angers, France

${ }^{\mathrm{i} I N S E R M ~ U 955, ~ E q u i p e ~ 1, ~ “ N e u r o p s y c h o l o g i e ~ I n t e r v e n t i o n n e l l e, ” ~ I M R B, ~ C r e ́ t e i l, ~ F r a n c e ~}$

${ }^{\mathrm{j}}$ Département d'Etudes Cognitives, ENS, Paris, France

${ }^{\mathrm{k}}$ Université Paris-Est XII, Faculté de Médecine, Créteil, France

${ }^{1}$ Service de Neurologie, CHU Henri Mondor, AP-HP, Créteil, France

mépartement de Neurosciences, CHU Henri Mondor, AP-HP, Créteil, France

*Corresponding author : Philippe ALLAIN, Unité de Neuropsychologie, Département de

Neurologie, Centre Hospitalier Universitaire, 4 rue Larrey, 49033 Angers Cedex 01. Telephone:

+33 (0)2 413555 46, Fax: +33 (0)2 413535 94, E-mail: PhAllain@ @ chu-angers.fr

Running title: Script knowledge in Huntington's disease 


\begin{abstract}
Introduction: Previous neuropsychological investigations have suggested that both the prefrontal cortex and the basal ganglia are involved in the management of script event knowledge required in planning behavior.

Methods: This study was designated to map, the correlations between resting-state brain glucose utilization as measured by FDG-PET (positron emission tomography) and scores obtained by means of a series of script generation and script sorting tasks in 8 patients with early Huntington's disease. Results: These patients exhibited a selectively greater impairment for the organizational aspects of scripts compared to the semantic aspects of scripts. We showed significant negative correlations between the number of sequencing, boundary, perseverative and intrusion errors and the metabolism of several cortical regions, not only including frontal, but also posterior regions. Conclusion: Our findings suggest that, within the fronto-striatal system, the cortical frontal regions are more crucial in script retrieval and script sequencing than the basal ganglia.
\end{abstract}

Keywords: Huntington's disease; script knowledge; PET; hypometabolism 


\section{Introduction}

In cognitive psychology, scripts are defined as a class of organized structures stored as knowledge networks for the representation of frequent activities undertaken by almost everyone such as "Going to a restaurant" (Schank and Abelson, 1977). They are similar in structure to lexical knowledge, and provide information about typical actors and their role within the scripts, particular instruments and objects important for the actions in scripts, typical locations in which scripts are performed, and typical sequences of actions.

Over the last 25 years the frontal lobes have been consistently shown to play a major role in script events processing. This involvement of frontal regions was reflected in several types of experimental tasks: script generation tasks (the subjects are asked to verbally generate, in the correct temporal order, the sequences of actions corresponding to scripts), script sorting tasks (the subjects are asked to select and cluster together, from a larger set, actions belonging to the same script) and/or script sequencing tasks (the subjects are asked to rearrange script actions in the correct temporal order).

So, in several studies script generation tasks (Godbout and Doyon, 1995; Sirigu et al., 1995; Fortin et al., 2003; Godbout et al., 2004; Zanini, 2008) have been associated with severe frontal pathology due to focal lesions (sequencing errors and/or violation errors and/or perseverations). Similar findings were reported by Godbout and Bouchard (1999), but only in a backward script generation task. However, normal sequencing performance has also been reported in patients with lesions mainly involving the frontal lobe (Zanini et al., 2002) and in TBI patients with dysexecutive disorders but without focal lesions in frontal regions (Cazalis et al., 2001). It should be noted however, that in all these studies except two (Chevignard et al., 2000; Godbout et al., 2004), patients were as accurate as healthy controls in terms of the number of relevant/central actions evoked. This suggests that patients' performances most likely reveal a deterioration of the script sequence (organization) rather than an inability to access intact script knowledge (generation).

Script sorting and/or sequencing tasks have also yielded contrasting results. Both impaired (Sirigu et al., 1996) and normal sorting performances (Sirigu et al., 1998) have been observed in 
patients with frontal lesions. Sequencing tasks were more consistently shown to be sensitive to frontal lobe lesions in both single-case studies (Humphreys and Forde, 1998; Rumiati et al., 2001) and group studies (Sirigu et al., 1995, 1996; Zalla et al., 1998; Zanini et al., 2002), although in some cases only for novel scripts (Swain et al., 1998). However, opposite findings were also reported in the above-mentioned group study with TBI patients (Cazalis et al., 2001) and in the single-case study (TBI patient JK) of Schwartz et al. (1995). In our own studies, we also found evidence for some of these findings (Allain et al., 1999).We asked patients with well-localized frontal lobe damage to sort script actions given with and without irrelevant actions, according to their putative order of execution. In fact, we found a dual dissociation. Some patients with frontal lesions made significantly more sorting errors than healthy controls and patients with posterior brain damage, but rejected the irrelevant actions. Other frontally lesioned patients exhibited a completely reversed pattern of performances. Lesion analysis revealed that three out of five left lateral frontal regions were consistently related to sequencing scores: the left prefrontal region (Brodmann's area [BA] 8, 9 and 46), the left premotor and rolandic region (BA 1, 2, 3, 4 and 6), and the left paraventricular region. The left paraventricular region and the left posterior orbital region (BA 11, 12, 13 and 47) were found to be strongly associated with intrusion errors. Later, in a second investigation (Allain et al., 2001), using several script sorting and sequencing tasks, we confirmed the role of the left frontal regions in script information sequencing and the involvement of the left orbital region in irrelevant action processing. Our findings suggest that the equivocal results found in the above-mentioned studies might be partially due to the neuroanatomical localization of the lesions within the frontal lobe. So, a left lateral lesion would entail low performances in action sequencing, whilst a left latero-orbital lesion would lead to low performances in aberrant action identification. However, our proposals remain highly speculative, because some of them were not examined by subsequent posthoc analyses.

Neuroimaging techniques have also shown frontal lobe activation in healthy subjects during the performance of script tasks. Investigating script sequencing in normal subjects with functional magnetic resonance imaging, Crozier et al. (1999) for example, found activations predominantly in 
bilateral middle and medial frontal gyrus areas (BA 8, 6, 44, 45) and superior temporal regions (BA 22). Knutson et al. (2004) replicated most of these findings using a very similar script-ordering task (BA 8, 6; see also Wood et al., 2005). Kuchinke et al., (2009) found that the processing of sequential relations between two script events activated the left frontal gyrus. In a positron emission tomography (PET) study, Partiot et al. (1996) found that when healthy subjects were asked to make a judgment about the correct temporal order of script actions, activations were seen in the right frontal lobe (BA 8), the left temporal gyrus (BA 22) and the middle temporal gyrus bilaterally (BA 21). The findings by Partiot et al. (1996) are inconsistent with the results of our own clinical studies (Allain et al., 1999; 2001).

Several neuropsychological studies have shown that script events processing was also impaired in patients with lesions in the basal ganglia. Zalla et al. (1998), for instance, studied the ability to organize script event sequences given with irrelevant actions in patients with mild to severe degrees of Parkinson's disease (PD), patients with frontal lobe lesions and healthy controls. Whereas the frontally lesioned patients manifested severe impairments (mainly sequencing errors and poor processing of distractors), the PD patients exhibited similarly significant but less severe deficits (see also Zalla et al., 2000). Godbout and Doyon (2000) investigated the role of the basal ganglia in the generation of scripts asking nondemented and nondepressed PD patients to verbally generate script actions under two experimental conditions; routine, forward script generation and nonroutine, backward script generation. PD patients generated scripts that were significantly deprived of contextual elements in the forward condition and made significantly more sequencing and perseverative errors in both the forward and backward conditions than healthy subjects. They also produced a significantly higher number of irrelevant intrusions than controls in both conditions,. In accordance with these studies, we showed (Allain et al., 2004) that nondemented and nondepressed patients with Huntington Disease (HD) committed significantly more chronological errors than normal controls when they were asked to re-establish the sequential order of series of script actions in the presence or in the absence of irrelevant actions. However, their ability to eliminate aberrant actions was intact. Taken together, these results suggest that script processing 
deficits seen in patients with basal ganglia lesions resemble those seen in frontal patients. A neuroanatomical explanation has been proposed to unravel the "frontal" profile of neuropsychological impairments in patients with lesions in the basal ganglia. This profile could be explained by strong anatomical evidence for the existence of five parallel and, at least partially, segregated circuits, which project from different areas of the frontal cortex through the basal ganglia and thalamus, and back to the frontal lobes (Alexander et al., 1986). Consequently, patients with lesions in the basal ganglia have particular difficulties performing frontal tasks (see for example Lawrence et al., 1996; Watkins et al., 2000) because their degenerative brain disorders affect fronto-striatal systems and reduce frontal activity. Normal ageing, which is also a condition that reduces frontal lobe activity (Tisserand and Jolles, 2003), has been reported to impair script events processing (Godbout et al., 2000; Helmes et al., 2006; Allain et al., 2007).

These findings also suggest that both the basal ganglia and the prefrontal cortex are involved in the organization of events within scripts. This idea is consistent with the theory developed by Norman and Shallice (1980) to explain the respective roles of the basal ganglia and the prefrontal cortex in action planning (for further elaborations, see Shallice, 1988, 2002; Shallice and Burgess, 1998; Cooper and Shallice, 2000). These authors have proposed two qualitatively distinct processes to determine which particular schema (script) will be activated to establish an appropriate plan of action. First, the Supervisory Attentional System (SAS), which modulates operations when situations are non-routine (novel or unusual) and which depend upon the prefrontal cortex. Second, Contention Scheduling (CS), an automatic process which modulates operations in familiar situations, depending upon the integrity of the basal ganglia. The model suggests that the frontal lobes are not involved in the storage of script information, which is represented in the retro-rolandic cortices that store semantic representations, but that they have a role in script information manipulation conditions making extensive demands on executive functions. In Norman and Shallice's terms, script sequencing tasks are expected to heavily involve executive functions. First, they require subjects to retrieve script-memory representations and to mentally simulate the whole temporal organization of actions in working memory. Second, subjects have to create a 
correspondence between each action written on a card and the internal abstract representations used as references. Third, during the sequencing stage, subjects must continually shift attention back and forth from the individual elements of the scripts to the general display dictated by the internal abstract script representations. Hence, the errors committed by frontal patients in script sequencing tasks might reflect executive impairments such as a difficulty in maintaining abstract representation in working memory or a diminished shifting ability. Further, the Norman and Shallice model would not predict an action specific sequencing deficit in script tasks following frontal lobe lesions, but overall sequencing deficits in task recruiting sequencing. On the other hand, the same model puts forward that the basal ganglia would be involved in situations where thought operations (schemas) automatically activated by contention scheduling are sufficient to carry out the task satisfactorily. According to Shallice (1982), damage to the basal ganglia should impair the patient's performance on a routine task. More specifically, basal ganglia damage would cause difficulties in maintaining the right script and inhibiting irrelevant ones (Godbout and Doyon, 2000).

In the light of the Norman and Shallice model, both prefrontal and subcortical regions seem involved in the script events processing impairments observed in patients with frontal or basal ganglia lesions, particularly in sequencing errors and poor distractor processing. However, the precise localization of the neural networks underlying these impairments remains unclear. First, findings concerning the role of frontal regions in script event processing are partially inconsistent. In addition, while the role of the prefrontal cortex in script generation, script sequencing and script sorting seems relatively well established, the role of sub-cortical structures such as the striatum and the way they impact on script information processing is still poorly understood. Finally, no neuroimaging data have been reported yet, showing that the basal ganglia play a role in script management.

In order to clarify these questions, we used Huntington Disease (HD) as a model to identify the cortical and sub-cortical regions whose dysfunction is responsible for impairments in script knowledge processing. It is well known that, pathologically, HD is characterized by neuronal loss and cerebral atrophy. Until recently, it was thought that the striatum was selectively targeted in the 
early stages of the disease (Aylward et al., 2000). However, there is increasing evidence that cortical areas, in particular frontal areas, are also affected (Rosas et al., 2002; Kassubek et al, 2004; Henley et al., 2008), suggesting that early HD patients have cortical and sub-cortical atrophy. In addition, we have already shown (Allain et al., 2004) that HD patients are impaired on script tasks. As a result, HD represents a reliable model to study the role of sub-cortical and cortical areas involved in script information processing.

To this end, we have used FDG-PET with statistical parametric mapping (SPM) to map the correlation between resting state brain glucose utilization and the scores obtained in several script generation and script ordering tasks in HD patients. Although the use of an activation paradigm (the execution of more specific script tasks during a fMRI session) might have been more appropriate to study fronto-striatal dysfunctions in HD patients during the execution of script tasks, in order to discriminate between cortical and sub-cortical contributions to action script processing, such studies are difficult to perform in these patients since task attention demands increase movement disorders critically. Therefore, as in previous studies, we relied on resting state metabolic data to perform our investigation. There is an abundant literature reporting the use of FDG-PET in the resting state to measure correlations with different cognitive and motor tasks in patients, either in HD patients (i.e., Teichmann et al., Brain 2008) or in many other brain diseases such as Alzheimer's disease (Desgranges et al., 2002; Mentis et al., 2002; Eustache et al., 2004; Lozza et al., 2004; Mosconi et al., 2004; Penniello, 1995; Piolino et al., 2007; Woo et al., 2010) mild cognitive impairment (Caselli et al., 2008; Nishi et al., 2010), Parkinson's Disease (Nagano-Saito et al., 2004; Huang et al., 2007; Abe et al., 2009) or multiple sclerosis (Blinkenberg et al., 2000). According to Magistretti et al. (1999), regional metabolic rate is a marker of integrated local synaptic activity and it is sensitive to both direct neuronal/synaptic damage and secondary functional disruption at synapses distant from the primary site of pathology. To our knowledge, the present study is the first attempt to discriminate between cortical and subcortical contributions to action script processing. We hypothesize that there is a hypometabolism in cerebral areas belonging to cortical-sub-cortical frontal circuits, contributing to explain script processing impairments. 


\section{Material and methods}

\subsection{Subjects}

\subsubsection{Patient group}

Eight patients with clinical symptoms and genetically identified HD were seen in this experiment. The 8 HD patients were 4 females and 4 males whose mean age was 38.6 years $(\mathrm{SD}=$ 7.5). Their mean number of years of education was $11.1(\mathrm{SD}=2.2)$, whereas mean estimated IQ was $106(\mathrm{SD}=7.6)$ on the AVB test (Beauregard, 1971). Subjects were early in the course of their disease: the mean duration of symptoms was 3.1 years $(\mathrm{SD}=2.9)$. Mean scores on the Unified Huntington's Disease Rating Scale (UHDRS; Huntington Study Group, 1996) activities of daily living and total functional capacity scales were $18.4 / 25(\mathrm{SD}=4.9)$ and $11.7 / 13(\mathrm{SD}=2.1)$ respectively, indicating mild functional impairment. The UHDRS total motor score was 33.8/124 $(\mathrm{SD}=20.6)$. The mean Mini Mental State Examination score was $26.6(\mathrm{SD}=1.7$; none of the patients scored below 24) and the mean Mattis Dementia Rating Scale score was 133.5 (SD = 6.7), indicating very mild cognitive impairments.

The cognitive part of the UHDRS was also administered to the patients. It comprises a neuropsychological battery of three subtests that measure several domains of executive functioning: spontaneous flexibility with a letter fluency task (Benton \& Hamsher, 1989), inhibition with the Stroop Color-Word Test (Stroop, 1935), selective attention and working memory with the SymbolDigit Modalities Test (SDMT, Smith, 1973). As can be seen in table 1, HD patients performed below the normal range on all these measures, suggesting the presence of executive disorders in these patients.

A French version of the Montgomery and Asberg Depression Rating Scale (MADRS) was also administered. Patients scored a mean of $10.9(\mathrm{SD}=3.9)$. Seven patients scored above the cutoff score of 15 for mild depression and one patient scored 15. HD patients also underwent a clinical assessment interview conducted by a psychiatrist, showing that none of them showed signs of significant depression. Three patients were receiving small doses of medication at the time of 
testing in order to reduce motor symptoms (Cyamémazine, Tiapride).

\section{Insert table 1 about here}

\subsubsection{Control subjects}

For the script sorting tasks, the patient group was compared with a group of 12 normal control volunteers (NC). These subjects were 7 females and 5 males whose mean age was 41.5 years $(\mathrm{SD}=12.4)$. Their mean total years of education were $11.1(\mathrm{SD}=3.3)$ and their mean IQ was $108(\mathrm{SD}=8.9)$ on the AVB test. None of them reported a history of nervous system disease or psychiatric problems. The HD patients and the NC groups did not differ significantly with respect to age $[t(18)=-0.58, P=0.56]$. The 2 groups were also matched on educational level $[t(18)=0.03$, $P=0.97]$ and IQ $[t(18)=-0.31, P=0.75]$.

For the script generation task, the patient group was compared with another group of $9 \mathrm{NC}$. These subjects were 6 females and 3 males whose mean age was 42.1 years $(\mathrm{SD}=7.2)$. Their mean number of years of schooling was $10.8(\mathrm{SD}=8.1)$ with a mean IQ of $109(\mathrm{SD}=9)$ on the AVB test. All subjects were free of serious medical illness. None of them had history of neurological and psychiatric illness. The 2 groups did not differ significantly with respect to age $[t(15)=-0.97, P=$ $0.34]$, educational level $[t(15)=0.18, P=0.85]$ and IQ $[t(15)=-.58, P=0.56]$.

The two groups of NC were also matched with respect to age [t(19) $=-0.13, P=0.89]$, education level $[t(19)=0.14, P=0.88]$ and IQ $[t(19)=-0.29, P=0.77]$.

Ethical permission was obtained from the French National Ethics Committee and the Créteil University Hospital Ethics Committee. Written informed consent was obtained from all patients. Normal control volunteers gave their consent to the neuropsychological study after being extensively informed, and the study was performed in conformity with the declaration of Helsinki.

\subsection{General procedure}

Within an interval of a few days at most, each HD patient underwent a neuropsychological examination including script generation and script sorting tasks and a PET measurement of resting CMRGlu. 


\subsection{Neuropsychological protocol}

\subsubsection{Script generation tasks}

The subjects had to describe how they would accomplish eight everyday activities: (1) sewing a button again, (2) writing a letter, (3) making an omelet, (4) making a cup of coffee with milk and sugar, (5) making a green salad, (6) making a ham sandwich, (7) doing the washing up and (8) polishing shoes. They were asked to verbally generate the sequence of actions (a list of 10 to 20 actions) corresponding to each everyday activity, which was written down by the experimenter. Respect of the temporal order of execution of the actions in each script was also demanded. Participants were first given an example (Doing morning routines). The order in which scripts had to be generated was randomized.

The mean total number of actions produced in each script was first considered. The eight scripts were then scored according to criteria that have been proposed by Bower et al. (1979), Roman et al. (1987) and Godbout and Doyon (2000). The norms used to score our scripts were based on a previous study with 274 francophone healthy control subjects (Allain, 2000), which was conducted in order to establish a corpus of script actions in the French language and to quantify four main characteristics of the actions within the activities (standardness, sequence, centrality and distinctiveness).

The semantic aspect of the script was measured using sorting criteria based on three types of actions (major, minor and trivial) and one type of error (relevant intrusion). To be included an action had to be mentioned by at least $18 \%$ of the healthy controls subjects of the normative study (Allain, 2000). Consistent with this normative study (Allain, 2000), actions that met this bottom criterion were subsequently classified as major (mentioned by more than $60 \%$ of the healthy control subjects), minor (mentioned by $40-59 \%$ of healthy control subjects), or trivial actions (mentioned by $18-39 \%$ of control subjects). By contrast, actions that did not met the inclusion criteria were listed as relevant intrusions, which either belonged to the particular script (relevant) or not (irrelevant). The number of actions in every semantic category, except for the relevant intrusions, was weighted; this number was therefore divided by the total number of actions that 
were generated for a particular script. Cognitive psychologists (Bower et al., 1979; Galambos, 1983; Corson, 1990) have shown that a script consists of major actions that constitute the heart or core of the semantic aspects of the script, with more minor and trivial actions providing context.

Difficulties in the temporal aspect of the script were evaluated in terms of sequencing errors (Roman et al., 1987), which correspond to a displacement in the logical sequence of actions within a script. The presence of boundary errors (when the generation of events stops short of the stated endpoint or extends beyond this point) was also used to evaluate the temporal dimension of the script. Furthermore, perseverative errors, which consist of actions that are repeated more than once in a script, were also measured.

\subsubsection{Script sorting tasks}

We used the normative data proposed by Bower et al. (1979) and Corson (1990) to construct two types of script sorting tasks.

In the first one, the subjects were asked to re-establish the sequential organization of 2 scripts ("Going shopping" and "Going to a restaurant"). These scripts contained 16 and 21 actions respectively. Subjects were presented with a shuffled array of cards with an action written on each card. The title (header) of the script was written on a separate card and was displayed in front of the subject during the task. Subjects were allowed to look at and read all cards once the examiner had finished laying them on the table. The subjects were then requested to arrange all the actions of each script in a correct sequential order.

In the second script sorting task, the subjects were also asked to arrange the actions of 2 different scripts in a correct sequential order, but this time both scripts were given with 3 aberrant or distractor items consisting of actions belonging to other scripts. The scripts used were "Going to a wedding" and "Changing a flat tire", each containing 12 actions. The subjects were not informed of the presence of the aberrant distractors which were "stamp a ticket", "have a swim", "place the jack" for the script "Going to a wedding" and "wipe oneself", "install the beach umbrella", "ask for the bill" for the script "Changing a flat tire". Subjects were presented all the actions of the script and the 3 aberrant distractors written on cards. The actions and the distractors were mixed and displayed on 
a table in random order. The title of the script was also written on a card displayed in front of the subject throughout the task. Subjects were allowed to look and read the cards when the examiner had finished laying them on the table and to arrange the cards in a correct sequence.

The mean number of sequencing errors (first and second task) and the mean number of distractor actions accepted (second task) were the performance parameters scored for each subject.

\subsection{PET scanning procedure}

As described elsewhere (Gaura et al., 2004), PET examinations were performed with a highresolution EXACT HR+ tomograph (CTI/Siemens) using a 3D acquisition. The subject's head was fixed using an individually molded headholder. All studies were carried out in a quiet, dark environment while the patients were in the resting state with the eyes closed. Metabolic images were acquired 30 to 50 minutes after intravenous injection of $118-280 \mathrm{MBq}$ of $\left[{ }^{18} \mathrm{~F}\right]$ fluoro-2-deoxyD-glucose $\left({ }^{18} \mathrm{FDG}\right)$.

\subsection{Statistical analysis}

\subsubsection{Cognitive data analysis}

The cognitive data were analyzed using the statistical package SPSS V5.1 (SPSS Inc., Chicago, Ill., USA). As these data were not normally distributed, the non-parametric MannWhitney U test was used to compare HD patients and HC groups. Chi-square tests were used to compare frequencies (proportions of types of actions generated and proportions of subjects making errors in the script generation tasks). The relationship between cognitive variables obtained in the script tasks was examined using non-parametric Spearman rank correlations.

\subsubsection{Image analysis}

Images were analyzed using the statistical parametric mapping software (SPM99; Welcome Department of Cognitive Neurology, London, UK, Friston, 1996). Briefly, images were transformed into Talairach's standard stereotaxic space (Talairach and Tournoux, 1988). The images were then smoothed with an $8 \times 8 \times 8 \mathrm{~mm}$ Gaussian filter to compensate for intersubject variability of brain anatomy (Friston, 1996).

First, we performed a voxel-by-voxel $t$-test comparison of brain metabolism of each patient 
with the brain metabolism obtained in 17 age-matched $(35.8 \pm 10.9$ years $)$ normal controls. The statistical threshold of each comparison was set at a conservative level of $\mathrm{P}<0.0005$.

Then, a correlation analysis using a multiple regression model was performed in the HD patients to investigate the relationships between cognitive scores and brain metabolism. The threshold of the correlation analysis was set at $\mathrm{P}<0.005$. Although, this threshold is not corrected for multiple comparisons (Bonferroni), our feeling is that it provides a good compromise considering the exploratory nature of the study. In other words, a Bonferroni correction would reveal only voxels with a $t$-value higher than 23.0 which is highly conservative and might elicit false negative results, i.e., hypometabolic regions that are truly associated with cognitive deficits but with a lower $t$-value. Accordingly, our results should be considered as exploratory and do not have the high degree of confidence that would be provided by a Bonferroni correction.

\section{Results}

\subsection{Script generation tasks}

\subsubsection{Semantic aspect}

The two groups did not differ significantly from each other with respect to the total number of actions generated per script $[U(15)=21.0, P=0.14]$. Mean numbers of actions per script produced by HD patients and $\mathrm{NC}$ were $10.1(\mathrm{SD}=3.8)$ and $10.8(\mathrm{SD}=2.1)$ respectively. The mean percentages of major, minor, and trivial actions as well as relevant intrusions that were generated for the 8 scripts (number of elements to a class of action/total number of elements $\mathrm{x} 100$ ) in the HD and normal control groups are reported in table 2. The semantic aspects of the script were examined using Chi-square tests. Comparison of proportions of all types of actions generated in both groups revealed a significant main effect of type of action [Chi $2=13.02, d f=4, P=0.01]$, suggesting that the two groups produced a different semantic organization of the script. Further post hoc analyses comparing the proportions of each type of actions produced in each group showed that HD patients generated a smaller proportion of minor elements [Chi $2=5.8, d f=1, P=0.01$ ], and a higher proportion of relevant intrusions [Chi $2=7.7, d f=1, P=0.005]$. There was no significant 
difference, however, between the proportions of major elements [Chi $2=0.08, d f=1, P=0.77]$, trivial elements $[$ Chi $2=0.05, d f=1, P=0.81]$ and irrelevant intrusions $[$ Chi $2=1.02, d f=1, P=$ $0.31]$.

\section{Insert table 2 about here}

\subsubsection{Temporal aspect}

A significant difference was found between HD and NC groups in sequence ordering $[U$ $(15)=0.0, P=0.0005]$ (Table 3). The proportion of HD patients manifesting sequencing errors (8/8) differed significantly from those (2/9) in the NC group [Chi $2=10.5, d f=1, P=0.001]$. Compared to the HC group, HD patients produced significantly more boundary errors $[U(15)=$ $16.0, P=0.02]$. In fact, a far greater proportion of patients in the HD group (5/8) stopped generation of events short of the stated end point, compared to the $\mathrm{HC}$ group $(1 / 9,[$ Chi $2=4.8, d f=1, P=$ 0.02). The mean number of perseverative errors was significantly higher in the HD group $[U(15)=$ $6.0, P=0.003]$. A statistical analysis comparing the proportion of HD patients $(7 / 8)$ making this kind of error to that of subjects in the HC group (1/9) reached significance $[$ Chi $2=9.92, d f=1, P=$ 0.001]. There was no gender difference in any of the scripts used in the generation task.

\section{Insert table 3 about here}

\subsection{Script sorting tasks}

In comparison with $\mathrm{HC}$ subjects, HD patients, committed significantly more errors of sequential organisation in all scripts (Table 4) (Going to a restaurant: $[U(18)=0.0, P=0.0002]$; Going shopping: $[U(18)=6.0, P=0.001]$; Going to a wedding: $[U(18)=4.5, P=0.0008]$; Changing a flat tire: $[U(18)=10.5, P=0.003])$. However, there was no significant difference in performance between HD patients and HC subjects in inhibiting irrelevant actions (Table 3) (Going 
to a wedding: $[U(18)=44.0, P=0.75]$; Changing a flat tire: $[U(18)=42.0, P=0.64])$. No gender difference emerged in any of the scripts used in the script sorting task.

\title{
Insert table 4 about here
}

\subsection{Correlations between script task scores and between task scores and executive scores}

Analyses of the relationship between script scores computed in both script tasks (HD group) revealed a significant correlation between the total number of sequencing errors produced in script generation tasks and the total number of sequencing errors produced in script sorting tasks ( $R h o=$ $.78, P=0.03)$. In addition, in the HD group, sequencing errors in the script sorting task correlated significantly with the total number of words produced in the fluency task of the UHDRS (Rho $=.79$, $P=0.02)$. There was also a significant correlation between the total number of sequencing errors in the script generation task and the scores in the fluency task $(R h o=.82, P=0.01)$ and in the symboldigit modalities test $(R h o=.72, P=0.04)$ of the UHDRS.

\subsection{Metabolism results}

Table 5 and Fig. 1 show the topography and the extent of the hypometabolism in patients compared with controls. SPM analysis revealed a marked reduction of activity in caudate and putamen nuclei. This significant hypometabolism was also demonstrated in multiple cortical areas: in the prefrontal regions in Brodmann's areas 10, 11, 47, 46, anterior cingulated cortices, parietal inferior area and in the sensorimotor and premotor regions, in Brodmann's areas 1, 2, 4, 6, 44.

\author{
Insert table 5 about here \\ Insert figure 1 about here
}


Significant correlations $(P<0.005$, uncorrected $)$ between cognitive data and brain regions were numerous and concerned principally cortical regions. Data produced by the SPM analysis are shown in Table 6.

Regarding script generation, we showed correlations between sequencing errors and metabolism of the right middle temporal gyrus but also with the left precentral gyrus and the inferior frontal gyrus bilaterally. The number of boundary errors in script generation is correlated with the hippocampal region bilaterally, the substantia nigra and the pons, and smaller regions in the prefrontal cortex (right middle and superior gyri, left middle and left precentral gyri), the cingulate gyrus bilaterally, the left temporal cortex (superior and inferior gyri) and the left parietal cortex (postcentral and inferior parietal gyri). Concerning perseverative errors (script generation), we showed correlations with the bilateral prefrontal cortex (left inferior and right superior gyri) and the right cingulate gyrus and the left postcentral gyrus. The number of sequencing errors is correlated to a hypometabolism of the occipital cortex (mainly cuneus and lingual gyrus) and the inferior frontal gyrus bilaterally but also small regions in right temporal cortex (middle and fusiform gyri) and parietal cortex (postcentral gyrus, inferior and superior gyri).

\section{Insert table 6 about here}

\section{Discussion}

The aim of the present study was to unravel the neural bases of script processing impairments in brain-damaged patients by mapping the correlations between resting-state brain glucose utilization measured by PET and measures of script knowledge across several script generation and script sorting tasks in a group of patients with HD. As mentioned in the introduction, although the use of more specific cognitive tasks during a fMRI session might have been more appropriate to study fronto-striatal dysfunctions in HD patients, such studies are difficult to perform with these subjects since attention demanded by the task increases movement disorders to an unacceptable degree. Therefore, as in previous studies of demented or HD patients, we relied on resting state 
metabolic data to perform our correlations. In the present study, the cognitive-metabolic correlations revealed that script processing impairments were mainly related to the dysfunction of cortical regions: primarily the lateral frontal cortex, but also temporal, parietal and occipital areas, regardless of the task. These results are discussed in the context of previous clinical and neuroimaging data and the framework of scripts.

\subsection{Characteristics of script impairments in $\mathrm{HD}$ patients}

The results of the present study suggest that script event processing by patients with HD is impaired when compared with age- and education-matched controls. Although the scripts generated by the patients contained a sufficient amount of major actions, they were characterized by a lack of detailed information and by an incoherent sequential organization, with several boundary and perseverative errors. Specifically, when patients with HD were asked to describe episodes like "Sewing a button again" or "Making an omelet", their description consisted of about ten major subsections per script. This is equivalent to the performance of controls, suggesting that the general organization of patients' script knowledge is relatively preserved. However, their descriptions, when compared to those of control subjects, were dominated by typical events and consisted of relatively fewer details (HD patients produced a smaller proportion of minor elements), with relatively more relevant intrusions (HD patients produced a higher proportion of relevant intrusions) and perseverative errors. In terms of response sequencing, HD patients tended to confuse the sequential order of events and to stop the generation of events short of the stated end point (boundary errors).

Script sequencing impairments were also observed in the script sorting tasks, in which HD patients committed significantly more sequencing errors than controls. However, in these tasks, their ability to eliminate aberrant actions was intact. A significant correlation indicated than sequencing difficulties in script generations tasks were consistent with sequencing problems in script sorting tasks in HD patients. 
The present results suggest that the performance of HD patients in script generation and script sorting tasks are most likely due to a deterioration of the script organization rather than an inability to access an intact semantic representation. In other words, it can be argued that the deficits described are consistent with the view that in HD patients fronto-striatal lesions selectively produce a greater impairment in the organizational aspects than in the semantic knowledge of a script. This finding is more consistent with a two-component model that dissociates script organizational processes from semantic script knowledge than with a one-component model in which all aspects of a script - including script content and the way in which this content is organized - are closely related. This claim is more consistent with Shallice's (1982) model.

In this theoretical model, script sequencing tasks are expected to heavily involve executive functions. Consistent with this proposition, we have found that sequencing errors correlated with flexibility (fluency task) and working memory measures (symbol-digit modalities test) of the UHDRS. This pattern of correlations resembles the one we have observed in elderly subjects using the same tasks (Allain et al., 2007). In this study, and in line with Shallice's (1982) model, we have suggested that ordering a preestablished sequence of actions requires the subjects to retrieve their script-memory representations and to simulate mentally the whole temporal structure of the actions in working memory. Then, during the sequencing stage, subjects must continually shift attention back and forth from the individual elements of the scripts to the general display dictated by the internal abstract script representations. We think that these suggestions could be applied to the current study. Hence, we can speculate that the sequence errors committed by HD patients might reflect a difficulty in maintaining abstract representations in working memory and a diminished shifting ability.

This pattern of cognitive deficits resembles the one seen after Parkinson Disease (PD), another clinical condition that disrupts functioning of the frontostriatal system. As mentioned before, several studies have shown than PD patients have preserved access to individual event knowledge required for planning, but significant impairments in well-defined aspects of script knowledge retrieval: poor processing of distractors (Zalla et al., 1998) in script sorting tasks, and 
poor sequencing in script sorting (Zalla et al., 1998) or script generation tasks (Godbout and Doyon, 2000). The latter authors, also showed that the scripts generated by PD patients were deprived of contextual elements, and contained more perseverative errors and irrelevant intrusions (Godbout and Doyon, 2000).

It is interesting to note that while sequencing errors are characteristic of both types of patients with basal ganglia lesions, there are some discrepancies between the present HD group and PD patients from the two previous studies (Zalla et al., 1998; Godbout and Doyon, 2000). First, in our script sorting tasks, HD patients discarded all the irrelevant actions. This result fits with our previous findings (Allain et al., 2004) in HD patients, but differs from the performance of PD patients in the study by Zalla et al. (1998). In this last study, the PD patients included one or more semantically related distractors in their script arrangements. Zalla et al. (1998) suggested that these difficulties of PD patients with distractors were due to an impairment of a switching mechanism that is necessary for processing information in parallel, more precisely to a difficulty in on-line comparison of event sequences from memory with those to be executed in the actual task. When interpreted in the light of this idea, the fact that our HD patients discarded most irrelevant actions suggests that their set shifting ability is intact. Second, in their script generation tasks, Godbout and Doyon (2000) found that PD patients produced more irrelevant intrusions than normal control subject. They proposed that this type of error was specific to a striatal dysfunction and consistent with Shallice's (1982) theory, in which damage to the basal ganglia should impair the ability to maintain script actions active in memory and to inhibit irrelevant ones. Our HD patients did not produce irrelevant intrusions, suggesting that their ability to maintain script actions active in memory and to inhibit irrelevant actions are better preserved than in PD patients. Consistent with this proposition, our HD patients discarded irrelevant actions in script sorting protocols.

Taken together, these discrepancies suggest that HD and PD have different consequences on script generation and script sorting abilities. To substantiate this idea, it is useful to compare script knowledge in PD and HD patients using the same script sorting and script generation tasks. This has not been the case to date. In the Zalla et al. (2000) study, for example, approximately 20 events 
composing 4 independent scripts were presented under different conditions (script events with headers, script events with headers including distractor events and script events without headers and distractors) in the script-event reconstitution task. In our script sorting tasks, 2 scripts containing each 12 actions with 3 distractors and 2 scripts containing 16 or 21 actions were used. In the script evocation study by Godbout and Doyon (2000), PD patients were asked to enumerate the actions of 6 familiar scripts in the correct chronological order and the actions of 6 other familiar scripts in the reverse order. As mentioned in the methological section of the present paper, we used 8 scripts in the script evocation task. These substantial differences in experimental protocols may have brought about the variation of performance profiles observed in PD and HD patients.

In summary, the behavioural results of the present study are coherent with the data of previous studies in patients with lesions of the basal ganglia (Zalla et al., 1998; Godbout and Doyon, 2000; Allain et al., 2004), reflecting a predominant impairment of script sequencing rather than a problem of access to script knowledge. Thus, at first view, our findings support the claim that the striatum has a role in script information sequencing. This claim is consistent with Shallice's (1982) model, which implies that damage to the basal ganglia impairs the ability to sequentially organise the actions of scripts. However, the fact that our HD patients discarded most irrelevant action suggests that their ability in maintaining the right script and inhibiting irrelevant ones is preserved. This finding is less consistent with Shallice's ideas.

\subsection{Neural bases of script deficits in HD patients}

First, it should be noted that the pattern of hypometabolism in our group of HD patients is in accordance with previous studies with PET in HD. The marked reduction of activity in caudate and putamen nuclei, together with a significant hypometabolism in multiple areas of prefrontal, anterior cingulated, parietal inferior, sensorimotor and premotor corticles have repeatedly been described in these patients (see for example, Kuhl et al., 1982; Mazziota et al., 1985; Kuwert et al., 1990; Martin et al., 1992; Gaura et al., 2004; Furtado et al., 2005).

We found that script generation and script sorting deficits correlated with hypometabolism in some of these cortical regions. Sequencing impairments, the most severe deficit in our cohort of HD 
patients in both tasks, were associated with hypometabolism in the inferior frontal gyrus (bilaterally) and the left precentral (middle) frontal gyrus. This finding supports our initial hypothesis and confirms the role of the frontal cortex in the processing of script sequences. In fact implications of frontal areas are consistently found in studies investigating the processing of order information in scripts (Crozier et al., 1999; Knutson et al., 2004; Partiot et al., 1996; Wood et al., 2005; Kuchinke et al., 2009). As suggested by Kuchinke et al. (2009), middle frontal gyrus functioning might be associated with mental representations of scenes in script based tasks when participants mentally imagine themselves performing the proposed actions (Crozier et al.,1999; Knutson et al., 2004). Crozier et al. (1999) and Knutson et al. (2004) had already suggested that the middle frontal gyrus might support the processing of higher level mental representations responsible for the timing or the sequencing of actions. In line with these propositions, our results show that hypometabolism in these regions is correlated with errors in the processing of sequential relations between script events.

The script sequencing deficit in our cohort of HD patients was associated with additional hypometabolism of temporal areas (right middle temporal gyrus) in the script generation task and with additional hypometabolism of parietal and occipital regions in the script sorting task. This suggests that other brain regions may contribute to sequencing abilities, thus casting a doubt upon the idea that the process of analysing sequential links in the script action domain is a specifically frontal function. In line with this proposition, Godbout et al. (2004) have recently found script temporal ordering impairments in patients with parietal lobe lesions. We have also found numerous sequencing errors in script sequencing tasks in patients with Alzheimer's disease (Allain et al., 2008. It is a matter of common knowledge that these patients have progressive tissue degeneration predominantly affecting temporoparietal areas (Braak and Braak, 1991; Gomez-Isla et al., 1996). Moreover, in an fMRI study conducted by Crozier et al. (1999), action sequence processing was also associated with activation of regions in the parietal and temporal cortices.

The fact that in our script sorting task sequencing errors were correlated with hypometabolism in the parietal lobe is consistent with past experiments, showing that this region 
was engaged for sequence learning. More precisely, Grafton et al. $(1995,1998)$ or Hazeltine et al. (1997) have shown that parietal cortex was engaged at the time of sequence encoding and sequence retrieval, independently of the stimulus cueing characteristics (spatially or symbolically cued). Thus, according to these authors (see also Bo et al., 2011), this region is crucial for forming sequence representation, but at an abstract level that best corresponds to the goals of the action rather than to specific movements. Scripts are abstract representations of goal-directed actions of everyday life. Script generation or sorting tasks require sequence retrieval. Therefore, we can speculate that parietal lobe would also be engaged in script sequence processing and that patients with parietal hypometabolism would be impaired in script sequencing tasks.

Consequently, while script sequencing tasks have been primarily associated with frontal lobe functioning until now (Grafman, 1989; Sirigu et al., 1995; Allain et al., 1999), the contributions of other brain regions should also be considered (see also Allain et al., 2008). The fact that boundary errors, perseverative errors and intrusion errors in our script generation task were correlated with hypometabolism in frontal and non frontal brain regions is also consistent with this proposition.

We found that boundary errors (script generation) were also correlated with hippocampal gyrus hypometabolism. This latter brain region has been generally related to memory retrieval (Henson, 2003; Sakai et al., 2002), as part of a common 'memory retrieval network' (Maquire and Mummery, 1999). Therefore, we can speculate that script generation might be associated with the activation of episodic memory representations. On the other hand, the association between impaired script generation and hyppocampal gyrus metabolism was relatively weak in the present study and further work is needed to confirm this idea.

Inconsistent with our initial hypotheses, we did not find correlations between script generation and script sorting impairments and hypometabolism in the caudate and putamen nuclei. This suggests that within the fronto-striatal system, the cortical frontal regions are more crucial in script processing than the basal ganglia. Such a finding is consistent with Shallice's (1982) theoretical model, in which the frontal lobes have an important role in script information manipulation conditions making extensive demands on executive functions needed in script 
generation and script sorting tasks. However, this model's prediction that basal ganglia damage should cause difficulties in maintaining the right script and inhibiting irrelevant ones is inconsistent with our results. In fact, our HD patients discarded irrelevant actions, including those of our script sorting task.

Finally, while the revised model proposed by Shallice (2002; Cooper and Shallice, 2000) implicates a degree of prefrontal cortical involvement in routine action processing, cognitivometabolic correlations in the current study are more in keeping with Grafman's (1999; Grafman, et al., 1993) model of managerial knowledge units (MKUs). Grafman (1999) argues that scripts can be considered as closely related concepts to MKUs, who can be defined as single units of memory representing syntactic and semantic aspects of event series. Grafman (1999) claims that frontal lesions damage the functional network that assembles MKU information into a correct syntax (that is into a sequentially correct sequence), but not the basic semantic representation of the script, which is stored in posterior cortical areas, but not in the basal ganglia. However, the fact that script sequencing deficits in HD patients were associated with additional hypometabolism of temporal, parietal and occipital areas suggests that other cortical regions may contribute to sequencing abilities.

In addition, our impression is that the pattern of cognitive deficits in HD patients is bears similar to the one seen in patients with prefrontal lesions. As mentioned in the introduction of this paper, several studies have shown that patients with frontal lesions have preserved access to script knowledge, but poor evaluation of the importance of events (Sirigu et al., 1995; Allain et al., 1999) and poor sequencing abilities (Godbout and Doyon, 1995; Sirigu et al., 1995). The only difference between frontally lesioned patients and HD patients is that the last group discarded irrelevant actions most correctly. The lesion analyses of our past studies (Allain et al., 1999, 2001) revealed that dorsolateral lesions of the frontal lobe were associated with script sequencing deficits, whilst orbital lesions were associated with impairments in eliminating irrelevant propositions (Allain et al., 1999; 2001). With regard to these data, the fact that in our script sorting task HD patients exhibited a selective impairment in their ability to produce temporally coherent sequences of actions without 
a deficit in their ability to eliminate irrelevant propositions, suggests that script processing impairments in HD could be better interpreted in terms of changes in the dorsolateral striatothalamo-cortical loop rather than in all-encompassing striato-thalamo-cortical loop deterioration. The dissociation of performance observed in the script sorting tasks used in the present study fits well with neuropsychological data obtained by Watkins et al. (2000) in HD patients early in the course of the disease. In these patients, these authors found a dissociation between impaired performance on a planning test (the one-touch Tower of London), that was strongly associated with the dorsolateral prefrontal cortex in functional imaging, and intact performance on a decision making task, which was associated to ventromedial prefrontal lesion. Our interpretation is consistent with what is known about the neuropathological progression of $\mathrm{HD}$, in which neuronal loss progresses in a dorsal-to-ventral direction (Hedreen and Folstein, 1995). Thereby, the dorsomedial striatum (a component of the dorsolateral prefrontal cortex loop circuitry) is affected earlier than the ventral striatum (a component of the orbitofrontal cortex loop circuitry). Following Hedreen and Folstein (1995) and Watkins et al. (2000), it would be very informative to study the performance on a script sorting tasks with distractors in later stages of HD. It could be predicted that deficits in inhibiting irrelevant actions would emerge as the disease spreads through the caudate nucleus.

As a limitation of our study we have to mention the small sample size and the modest statistical power of our correlations between resting-state brain glucose utilization and script task scores. As a result, our findings should be considered as exploratory. In addition, we did not control for the frequency and/or familiarity of the used scripts. Although we selected daily-life scripts, their frequency of execution may widely vary. For example, an activity such as "Sewing a button again" includes a sequence of actions that are executed less often than "Going Shopping". In a recent study, Krueger et al. (2007) showed that event frequency modulates the sequence processing of daily-life activities in the human medial prefrontal cortex. The authors revealed that sub-regions of the medial prefrontal cortex were differentially engaged in processing event sequence knowledge, depending on how often the corresponding daily life activities are performed. The anterior medial 
prefrontal area (BA 10) was differentially activated for low frequency and the posterior medial prefrontal area10 for high frequency daily life activities. Krueger et al. (2007) concluded that subregions of the medial prefrontal cortex are differentially engaged in processing event sequence knowledge depending on how often the activity was reportedly performed in daily life. Therefore, we can assume that we would have observed different patterns of cognitivo-metabolic correlations if we had taken into account the variations of frequency/familiarity in our scripts. However, in the present work, no correlations emerged between sequencing errors and hypometabolism in the anterior medial prefrontal area. In addition, while we used stereotypical male scripts ("Changing a flat tire") and stereotypical female scripts ("Doing the washing up") in our script task, no gender differences emerged, suggesting that the degree of variation in the execution of an action has no incidence on the likelihood of the subject sequencing it correctly in the script. This conclusion is only an hypothesis. A study using scripts that are based upon tasks that are better controlled in terms of frequency/ familiarity would be required in order to disentangle this problem.

\section{Conclusion}

In conclusion, our findings provide evidence for a selectively larger impairment for the organizational aspects compared to semantic knowledge of script in HD patients. Script generation and script ordering are affected early in the course of the disease, and the deficits observed are correlated with reduced metabolism in a distributed functional network mainly including cortical regions. Our findings should motivate further work, including longitudinal brain imaging, in order to clarify when script manipulation deficits become manifest and how their brain substrate evolves over time. From a clinical point of view, script tasks may be useful in determining the onset of cognitive involvement and in tracking disease progression in HD. A better understanding of the pattern of deficits might also have some implications for anticipating the everyday life difficulties encountered by HD patients. 
Acknowledgements: The MIG-HD trial is granted through two PHRC AOM00139 and AOM 04021 from the DRCD (Assistance Publique- Hôpitaux de Paris) and the support of the AFM. The management center involves: A.C. Bachoud-Lévi (Principal investigator), S. Palfi, P. Remy, M. Peschanski, P. Hantraye, J.P. Lefaucheur, D. Challine, P. Maison. CROs were: A. Rialland, D. Schmitz. Data manager: G. Dolbeau. The Sites PI are : A.C. Bachoud-Lévi, S. Palfi, ( Créteil), P. Krystkowiak, S. Blond, (Lille), J.F. Démonet, J.C. Sol (Toulouse), C. Verny, P. Menei (Angers), P. Damier, Y. Lajat (Nantes); F. Supiot, M. Levivier (Bruxelles). 


\section{References}

Abe, N., Fujii, T., Hirayama, K., Takeda, A., Hosokai, Y., Ishioka, T., Nishio, Y., Suzuki, K., Itoyama, Y., Takahashi, S., Fukuda, H., \& Mori, E. (2009). Do parkinsonian patients have trouble telling lies? The neurobiological basis of deceptive behaviour. Brain, 132, 1386-1395.

Alexander, G.E., Delong, M.R., \& Strick, P.L.,1986. Parallel organization of functionally segregated circuits linking basal ganglia and cortex. Annual Review of Neurosciences, 9, 357381.

Allain, P. (2000). Pathologie frontale et utilisation des schémas routiniers d'action: Script et pathologie frontale. Thèse de Doctorat de Neuropsychologie. Université Claude Bernard: Lyon I.

Allain, P., Berrut, G., Etcharry-Bouyx, F., Barré, J., Dubas, F., \& Le Gall, D. (2007). Executive functions in normal aging: An examination of script sequencing, script sorting and script monitoring. Journal of Gerontology, Psychological Sciences and Social Sciences, 62, 187-190.

Allain, P., Le Gall, D., Etcharry-Bouyx, F., Aubin, G., \& Emile, J. (1999). Mental representation of knowledge following frontal-lobe lesion: Dissociations on tasks using scripts. Journal of Clinical and Experimental Neuropsychology, 21, 5, 643-665.

Allain, P., Le Gall, D., Foucher, C., Etcharry-Bouyx, F., Barré, J., Dubas, F., \& Berrut, G. (2008). Script representation in patients with Alzheimer's disease. Cortex, 44, 294-304.

Allain, P., Le Gall, D., Etcharry-Bouyx, F., Forgeau, M., Mercier, P., \& Emile, J. (2001). Influence of the centrality and distinctiveness of actions on script sorting and ordering in patients with frontal lobe lesions. Journal of Clinical and Experimental Neuropsychology, 23, 4, 465-483.

Allain, P., Verny, C., Aubin, G., Bonneau, D., Dubas, F., \& Le Gall, D. (2004). Arrangement de scripts dans la maladie de Huntington. Revue Neurologique, 160, 434-440.

Aylward, E.H., Codori, A.M., Rosenblatt, A., Sherr, M., Brandt, J., Stine, O.C., Barta,P.E., Pearlson, G.D., \& Ross, C.A. (2000). Rate of caudate atrophy in presymptomatic and symptomatic stages of Huntington's disease. Movement Disorders, 15, 552-560.

Beauregard, A. (1971). Les Tests des Automatismes Verbaux. Issy les Moulineaux: Editions Scientifiques et Psychotechniques.

Benton, A.L., \& Hamsher, K. (1989). Multilingual aphasia examination. Iowa: AJA Associates.

Blinkenberg, M., Rune, K., Jensen, C.V., Ravnborg, M., Kyllingsbaek, S., Holm, S., Paulson, O.B., \& Sørensen, P.S. (2000). Cortical cerebral metabolism correlates with MRI lesion load and cognitive dysfunction in MS. Neurology, 54, 558-564.

Bo, J., Peltier, S.J., Noll, D.C. \& Seidler, R.D. (2011). Symbolic representations in motor sequence learning. Neuroimage, 54, 417-426.

Bower, G. H., Black, J. B., \& Turner, T. J. (1979). Scripts in memory for texts. Cognitive Psychology, 11, 177-220.

Braak, H., \& Braak, E. (1991). Alzheimer's disease affects limbic nuclei of the thalamus. Acta Neuropathologica, 81, 261-268.

Cardebat, D., Doyon, B., Puel, M., Goulet, P., \& Joanette, Y. (1990). Formal and semantic lexical evocation in normal subjects. Performance and dynamics of production as a function of sex, age and educational level. Acta Neurologica Belgica, 90, 207-217. 
Caselli, R.J., Chen, K., Lee, W., Alexander, G.E., \& Reiman, E.M. (2008). Correlating cerebral hypometabolism with future memory decline in subsequent converters to amnestic pre-mild cognitive impairment. Archives of Neurology, 65, 1231-1236.

Cazalis, F., Azouvi, P., Sirigu, A., Agar, N., \& Burnod, Y. (2001). Script knowledge after severe traumatic brain injury. Journal of the International Neuropsychological Society, 7, 795-804.

Chevignard, M., Pillon, B., Pradat-Diehl, P., Taillefer, C., Rousseau, S., Le Bras, C., \& Dubois, B. (2000). An ecological approach to planning dysfunction: Script execution. Cortex, 36, 649-669.

Corson, Y. (1990). The structure of scripts and their constituent elements. Cahiers de Psychologie Cognitive, 2, 157-183.

Cooper, R. P., \& Shallice, T. (2000). Contention scheduling and the control of routine activities. Cognitive Neuropsychology, 17, 297-338.

Crozier, S., Sirigu, A., Lehericy, S., Van De Moortele, P. F, Pillon, B., Grafman, J., Agid, Y., Dubois, B., \& Lebihan, D. (1999). Distinct prefrontal activations in processing sequence at the sentence and script level: An fMRI study. Neuropsychologia, 37, 1469-1476.

Desgranges, B., Baron, J.C., Giffard, B., Chételat, G., Lalevée, C., Viader, F., de la Sayette, V., \& Eustache, F. (2002). The neural basis of intrusions in free recall and cued recall: A PET study in Alzheimer's disease. Neuroimage, 17, 1658-1664.

Eustache, F., Piolino, P., Giffard, B., Viader, F., de la Sayette, V., Baron, J. C., \& Desgranges, B. (2004). 'In the course of time': A PET study of the cerebral substrates of autobiographical amnesia in Alzheimer's disease. Brain, 127, 1549-1560.

Fortin, S., Godbout, L., \& Braun, C.M.J. (2003). Cognitive structure of executive deficits in frontally lesioned head trauma patients performing activities of daily living. Cortex, 39, 273-291.

Friston, K. J. (1996). Statistical parametric mapping and other analysis of functional imaging data. In A. W. Toga \& J. C. Mazziotta (Eds.), Brain mapping. The methods (pp. 363-386). San Diego: Academic Press.

Furtado, S., Sossi, V., Hauser, R. A., Samii, A., Schulzer, M., Murphy, C. B., Freeman, T. B., \& Stoessl, A. J. (2005). Positron emission tomography after fetal transplantation in Huntington's disease. Annals of Neurology, 58, 331-337.

Galambos, J. A. (1983). Normative studies of six characteristics of our knowledge of common activities. Behavioral Reasearch, Methods and Instrumentation, 15, 327-340.

Gaura, V., Bachoud-Levi, A. C., Ribeiro, M. J., Nguyen, J. P., Frouin, V., Baudic, S., Brugieres, P., Mangin, J. F., Boisse, M. F., Palfi, S., Cesaro, P., Samson, Y., Hantraye, P., Peschanski, M., \& Remy, P. (2004). Striatal neural grafting improves cortical metabolism in Huntington's disease patients. Brain, 127, 65-72.

Godbout, L., \& Bouchard, C. (1999). Processing time and space components of semantic memory: A study of frontal-loberelated impairments. Brain and Cognition, 40, 136-139.

Godbout, L., Cloutier, P., Bouchard, C., Braun, C. M. J., \& Gagnon, S. (2004). Script generation following frontal and parietal lesions. Journal of Clinical and Experimental Neuropsychology, $26,857-873$.

Godbout, L., Doucet, C., \& Fiola, M. J. (2000). The scripting of activities of daily living in normal aging: Anticipation and shifting deficits with preservation of sequencing. Brain and Cognition, $43,220-224$.

Godbout, L., \& Doyon, J. (1995). Mental representation of knowledge following frontal-lobe or postrolandic lesions. Neuropsychologia, 33, 1671-1696.

Godbout, L., \& Doyon, J. (2000). Defective representation of knowledge in Parkinson's disease: evidence from a script-production task. Brain and Cognition, 44, 490-510. 
Golden, C.J. (1978). Stroop color and word test. Chicago: Stoelting.

Gomez-Isla, T., Price, J. L., McKeel, D. W. J, Morris, J. C., Growdon, J. H., \& Hyman, B. T. (1996). Profound loss of layer II enthorhinal cortex neurons occurs in very mild Alzheimer's disease. Journal of Neuroscience, 16, 4491-4500.

Grafman, J. (1989). Plans, actions and mental sets: Managerial knowledge units in the frontal lobes. In E. Perecman (Ed.), Integrating theory and practice in clinical neuropsychology (pp. 93-138). Hillsdale, NJ: Lawrence Erlbaum Associates.

Grafman, J. (1999). Experimental assessment of adult frontal lobe function. In B. L. Miller \& J. L. Cummings (Eds.), The human frontal lobes: Functions and disorders (pp. 321-344). New York: Guilford.

Grafman, J., Sirigu, A., Spector, L., \& Hendler, J. (1993). Damage to the prefrontal cortex leads to decomposition of structured event complexes. Journal of Head Trauma Rehabilitation, 8, 73-87.

Grafton, S.T., Hazeltine, E., \& Ivry, R.B. (1995). Functional mapping of sequence learning in normal humans. Journal of Cognitive Neuroscience, 7, 497-510.

Grafton, S.T., Hazeltine, E., \& Ivry, R.B. (1998). Abstract and effector-specific representations of motor sequences identified with PET. Journal of Neuroscience, 18, 9420-9428.

Hazeltine, E., Grafton, S.T., \& Ivry, R. (1997). Attention and stimulus characteristics determine the locus of motor-sequence encoding : A PET study. Brain, 120, 123-140

Hedreen, J. C., \& Folstein, S. E. (1995). Early loss of neostriatal striosome neurons in Huntington's disease. Journal of Neuropathology and Experimental Neurology, 54, 105-120.

Henley, S.M., Wild, E.J., Hobbs, N.Z., Warren, J.D., Frost, C., Scahill, R.I., Ridgway, G.R., MacManus, D.G., Barker, R.A., Fox, N.C., \& Tabrizi, S.J. (2008). Defective emotion recognition in early HD is neuropsychologically and anatomically generic. Neuropsychologia, 46, 2152-2160.

Helmes, E., Bush, J. D., Pike, D. L., \& Drake, D. G. (2006). Gender differences in performance of script analysis by older adults. Brain and Cognition, 62, 206-213.

Henson, R. N. A., Cansino, S., Herron, J. E., Robb, W. G. K., \& Rugg, M. D. (2003). A familiarity signal in human anterior medial temporal cortex? Hippocampus, 13, 2, 301-304.

Huang, C., Mattis, P., Tang, C., Perrine, K., Carbon, M., \& Eidelberg, D. (2007). Metabolic brain networks associated with cognitive function in Parkinson's disease. Neuroimage, 34,714-723.

Huntington Study Group. (1996). Unified Huntington's Disease Rating Scale: Reliability and consistency. Huntington Study Group. Movement Disorders, 11, 136-142.

Humphreys, G. W., \& Forde, E. M. E. (1998). Disordered action schema and action disorganisation syndrome. Cognitive Neuropsychology, 15, 771-811.

Kassubek, J., Gaus, W., \& Landwehrmeyer, G.B. (2004). Evidence formore widespread cerebral pathology in early HD: An MRI-based morphometric analysis. Neurology, 62, 523-524.

Knutson, K. M., Wood, J. N., \& Grafman, J. (2004). Brain activation in processing temporal sequence: An fMRI study. NeuroImage, 23, 1299-1307.

Krueger, F., Moll, J., Zahn, R., Heinecke, A., \& Grafman, J. (1997). Event frequency modulates the processing of daily life activities in human medial prefrontal cortex. Cerebral Cortex, 17, 23462353.

Kuchinke, L., van der Meer, E. \& Krueger, F. (2009). Differences in processing of taxonomic and sequential relations in semantic memory: An fMRI investigation. Brain and Cognition, 69, 245261. 
Kuhl, D. E., Phelps, M. E., Markham, C. H., Metter, E. J., Riege, W. H., Winter, J. (1982). Cerebral metabolism and atrophy in Huntington's disease determined by 18FDG and computed tomographic scan. Annals of Neurology 12, 425-434.

Kuwert, T., Lange, H. W., Langen, K. J., Herzog, H., Albrecht, A., \& Feinendegen, L. E. (1990). Cortical and subcortical glucose consumption measured by PET in patients with Huntington's disease. Brain, 113, 1405-1423.

Lawrence, A. D., Sahakian, B. J., Hodges, J. R., Rosser, A. E., Lange, K. W., \& Robbins, T. W. (1996). Executive and mnemonic functions in early Huntington's disease. Brain, 199, 16331645.

Lozza, C., Baron, J.C., Eidelberg, D., Mentis, M.J., Carbon, M., \& Marie, R.M. (2004). Executive processes in Parkinson's disease: FDG-PET and network analysis. Human Brain Mapping, 22, 236-245.

Magistretti, P.J., Pellerin, L., Rothman, D.L., \& Shulman, R.G. (1999). Energy on demand. Science, 283: 496-497.

Maguire, E. A., \& Mummery, C. J. (1999). Differential modulation of a common memory retrieval network revealed by positron emission tomography. Hippocampus, 9, 54-61.

Martin, W. R. W., Clark, C., Ammann, W., Stoessl, A. J., Shtybel, W., \& Hayden, M. R. (1992). Cortical glucose metabolism in Huntington's disease. Neurology, 42, 223-229.

Mazziotta, J. C., Phelps, M. E., Pahll, J. J., Huang, S. C., Baxter, L. R., Riege, W. H., Hoffman, J. M., Khul, D. E., Lanto, A. B., Wapenski, J. A. et al. (1987). Reduced cerebral glucose metabolism in asymptomatic subjects at risk for Huntington's disease. The New England Journal of Medicine, 316, 357-362.

Mentis, M.J., McIntosh, A.R., Perrine, K., Dhawan, V., Berlin, B., Feigin, A., Edwards, C., Mattis, P., \& Eidelberg, D. (2002). Relationships among the metabolic patterns that correlate with mnemonic, visuospatial, and mood symptoms in Parkinson's disease. American Journal of Psychiatry, 159, 746-754.

Mosconi, L., Pupi, A., De Cristafaro, M.T., Fayyaz, M., Sorbi, S., \& Herholtz, K. (2004). Functional interactions of the entorhinal cortex: an 18F-FDG PET study on normal aging and Alzheimer's disease. Journal of Nuclear Medecine, 45, 382-392.

Nishi, H., Sawamoto, N., Namiki, C., Yoshida, H., Dinh, H.D., Ishizu, K., Hashikawa, K., \& Fukuyama, H. (2010). Correlation between cognitive deficits and glucose hypometabolism in mild cognitive impairment. Journal of Neuroimaging, 20, 29-36.

Nagano-Saito, A., Kato, T., Arahata, Y., Washimi, Y., Nakamura, A., Abe, Y., Yamada, T., Iwai, K., Hatano, K., Kawasumi, Y., Kachi, T., Dagher, A., \& Ito, K. (2004). Cognitive- and motorrelated regions in Parkinson's disease: FDOPA and FDG PET studies. Neuroimage, 22, 553-561.

Norman, D. A., \& Shallice, T. (1980). Attention to action: Willed and automatic control of behaviour. Center for human information processing (Technical report $n^{\circ} 99$ ). (Reprinted in revised form. In R. J. Davidson, G. E. Schwartz \& D. Shapiro (Eds.), Consciousness and selfregulation. Advances in research and theory, (1986), 4 (pp. 1-18). New York: Plenum Press.

Partiot, A., Grafman, J., Sadato, N., Flitman, S., \& Wild, K. (1996). Brain activation during script event processing. NeuroReport, 7, 761-766. 
Penniello, M.J., Lambert, J., Eustache, F., Petit-Taboué, M.C., Barré, L., Viader, F., Morin, P., Lechevalier, B., \& Baron, J.C. (1995). A PET study of the functional neuroanatomy of writing impairment in Alzheimer's disease. The role of the left supramarginal and left angular gyri. Brain, 118, 697-706.

Piolino, P., Chetelat, G., Matuszewski, V., Landeau, B., Mezenge, F., Viader, F., de la Sayette, V., Eustache, F., \& Desgranges, B. (2007). In search of autobiographical memories: a PET study in the frontal variant of frontotemporal dementia. Neuropsychologia, 45, 2730-2743.

Roman, M., Brownell, H. H., Potter, H. H., Seibold, M. S., \& Gardner, H. (1987). Script knowledge in right hemisphere damage and in normal elderly adults. Brain and Language, 31, 151-170.

Rumiati, R. I., Zanini, S., Vorano, L., \& Shallice, T. (2001). A form of ideational apraxia as a selective deficit of contention scheduling. Cognitive Neuropsychology, 18, 617-642.

Sakai, K., Rowe, J. B., \& Passingham, R. E. (2002). Parahippocampal reactivation signal at retrieval after interruption of rehearsal. Journal of Neuroscience, 22, 15, 6315-6320.

Schank, R. C., \& Abelson, R. (1977). Scripts, plans, goals, and understanding. Hillsdale, NJ: Erlbaum.

Schwartz, M. F, Montgomery, M. W., Fitzpatrick-Desalme, E. J, Ochipa, C., Coslett, H. B., \& Mayer, N. H. Analysis of a disorder of everyday action. Cognitive Neuropsychology, 12, 863892.

Shallice, T. (1982). Specific impairments of planning. Philosophical Transactions of the Royal Society of London B, 298, 199-209.

Shallice, T. (1988). From neuropsychology to mental structures. Cambridge: Cambridge University Press.

Shallice, T. (2002). Fractionation of the supervisory system. In D. T. Stuss (Ed.), Principles of frontal lobe function (pp. 261-277). New York: Oxford University Press.

Shallice, T., \& Burgess, P.W. (1998). Domain of supervisory processes and the temporal organization. In A. C. Roberts, T. W. Robbins \& L. Weiskrantz (Eds.), The frontal cortex (pp. 22-35). Oxford: Oxford University Press.

Sirigu, A., Cohen, L., Zalla, T., Pradat-Diehl, P., Van Eeckhout, P., Grafman, J., \& Agid, Y. (1998). Distinct frontal regions for processing sentence syntax and story grammar. Cortex, 34, 771-778.

Sirigu, A., Zalla, T., Pillon, B., Grafman, J., Agid, Y., \& Dubois, B. (1995). Selective impairments in managerial knowledge following pre-frontal cortex damage. Cortex, 31, 301-316.

Sirigu, A., Zalla, T., Pillon, B., Grafman, J., Agid, Y., \& Dubois, B. (1996). Encoding of sequence and boundaries of scripts following prefrontal lesions. Cortex, 32, 297-310.

Smith, A. (1973). Symbol digit modalities test manual. Los Angeles: Western Psychological Services.

Stroop, J.R. (1935). Studies of interference in serial verbal reactions. Journal of Experimental Psychology, 18, 643-662.

Swain, S. A., Polkey, C. E., Bullock, P., \& Morris, R. G. (1998). Recognition memory and memory for order in script-based stories following frontal lobe excisions. Cortex, 34, 25-45.

Talairach, J., \& Tournoux, P. (1988). Co-planar stereotaxic atlas of the human brain. Stuttgard: Thieme.

Tisserand, D. J., \& Jolles, J. (2003). On the involvement of prefrontal networks in cognitive aging. Cortex, 39, 1107-1128.

Teichmann, M., Gaura, V., Démonet, J.F., Supiot, F., Delliaux, M., Verny, C., Renou, P., Remy, P., \& Bachoud-Lévi, A.C. (2008). Language processing within the striatum: Evidence from a PET 
correlation study in Huntington's disease. Brain, 131, 1046-1056.

Wood, J. N., Knutson, K. M., \& Grafman, J. (2005). Psychological structure and neural correlates of event knowledge. Cerebral Cortex, 15, 1155-1161.

Zalla, T., Sirigu, A., Pillon, B., Dubois, B., Grafman, J., \& Agid, Y. (1998). Deficits in evaluating pre-determinated sequences of script events in patients with Parkinson's disease. Cortex, 34, 621-628.

Zalla, T., Sirigu, A., Pillon, B., Dubois, B., Agid, Y., \& Grafman, J. (2000). How patients with Parkinson's disease retrieve and manage cognitive event knowledge. Cortex, 36, 163-179.

Zanini, S. (2008). Generalized script sequencing deficits following frontal lobe lesions. Cortex, 44, 140-149.

Zanini, S., Rumiati, R.I., \& Shallice, T. (2002). Action-sequencing deficit following frontal lobe lesion. Neurocase, 8, 88-99.

Watkins, L.H.A., Rogers, R.D., Lawrence, A.D., Sahakian, B.J., Rosser, A.E., \& Robbins, T.W. (2000). Impaired planning but intact decision making in early Huntington's disease: Implication for specific fronto-striatal pathology. Neuropsychologia, 38, 1112-1125.

Wechsler, D. (1981). Wechsler adult intelligence scale-revised manual. New York: Psychological Corporation.

Woo, B.K., Harwood, D.G., Melrose, R.J., Mandelkern, M.A., Campa, O.M., Walston, A., \& Sultzer, D.L. (2010). Executive deficits and regional brain metabolism in Alzheimer's disease. International Journal of Geriatric Psychiatry, 25, 1150-1158. 
Table 1

Mean UHDRS executive scores (with standard deviations in parentheses) for HD patients

\begin{tabular}{llc}
\hline & HD Patients & Normal \\
& & published range \\
\hline Stroop interference (Total correct in $45 \mathrm{sec})$. & $25.6(7.9)$ & $>35^{\mathrm{a}}$ \\
Fluency PRV (Total correct in $360 \mathrm{sec}$.) & $40.2(13)$ & $>56^{\mathrm{b}}$ \\
Symbol-digit modalities test (Total correct in $90 \mathrm{sec})$. & $26.7(8.1)$ & $>37^{\mathrm{c}}$ \\
\hline
\end{tabular}

a : Norms are issued from Golden (1978); b : Norms are issued from Cardebat, Doyon, Puel, Goulet \& Joanette (1990); c : Norms are issued from Wechsler (1981). 
Table 2

Mean percentage (with standard deviations in parentheses) of major, minor, and trivial actions, as well as relevant intrusions that were generates for each script in the HD and NC groups

\begin{tabular}{lccc}
\hline & HD & NC & \\
Variables & Patients & Subjects & $P$ \\
\hline Major & $62.2(11.4)$ & $60.2(7.3)$ & 0.77 \\
Minor & $11.0(3.7)$ & $24.4(5.5)$ & 0.01 \\
Trivial & $9.6(4.7)$ & $11.0(2.9)$ & 0.81 \\
Relevant intrusions & $14.2(6.8)$ & $3.4(1.6)$ & 0.005 \\
Irrelevant intrusions & $3.0(1.2)$ & $1.0(0.2)$ & 0.31 \\
\hline
\end{tabular}


Table 3

Sequencing, boundary, and perseverative errors (means with standard deviations in parentheses) in the HD and NC groups

HD NC

Variable

Patients

Subjects

$P$

Sequencing errors

Mean error (SD)

$7.9(2.7)$

$0.1(0.3)$

0.0005

Number of subjects

$8 / 8$

$2 / 9$

0.001

Boundary errors

Mean error (SD)

$1.0(0.9)$

$0.1(0.3)$

0.02

Number of subjects

$5 / 8$

$1 / 9$

0.02

Perseverative errors

Mean error (SD)

$4.1(2.9)$

$0.2(0.7)$

0.003

Number of subjects

$7 / 8$

$1 / 9$

0.001 
Table 4

Script sorting task scores (means with standard deviations in parentheses)

\begin{tabular}{llll}
\hline & HD & NC & \\
& Patients & Subjects & $P$ \\
\hline Sequencing errors & & & \\
"Going to a restaurant" & $3.6(1.2)$ & $0.3(0.5)$ & 0.0002 \\
"Going shopping" & $2.1(1.3)$ & $0.2(0.4)$ & 0.001 \\
"Going to a wedding" & $1.7(0.7)$ & $0.2(0.4)$ & 0.0008 \\
"Changing a flat tire" & $2.6(1.7)$ & $0.2(0.4)$ & 0.003 \\
Total & $10.1(2.9)$ & $1.1(0.9)$ & 0.0002 \\
Irrelevant actions used & & & 0.75 \\
"Going to a wedding" & & $0.2(0.4)$ & 0.64 \\
"Changing a flat tire" & $0.6(0.5)$ & $0.5(0.5)$ & 0.21 \\
\hline
\end{tabular}


Table 5

SPM analysis: local peaks in the whole brain obtained with the t-test comparison

\begin{tabular}{|c|c|c|c|c|c|c|c|c|c|}
\hline \multirow[t]{2}{*}{ Anatomical Region } & \multirow[t]{2}{*}{ Side } & \multirow[t]{2}{*}{$\mathrm{BA}$} & \multicolumn{3}{|c|}{ Talairach coordinates } & \multirow[t]{2}{*}{ Z score } & \multirow{2}{*}{$\begin{array}{c}\text { Number of } \\
\text { voxels }\end{array}$} & \multirow{2}{*}{$\begin{array}{c}\text { Corrected } P \\
\text { (cluster level) }\end{array}$} & \multirow{2}{*}{$\begin{array}{l}\text { Corrected } P \\
\text { (voxel level) }\end{array}$} \\
\hline & & & $x$ & $y$ & $z$ & & & & \\
\hline Caudate & $\mathrm{L}$ & & -12 & 14 & 2 & Inf & 2083 & 0.000 & 0.000 \\
\hline Caudate & $\mathrm{L}$ & & -14 & 6 & 14 & 7.79 & & & 0.000 \\
\hline Caudate & $\mathrm{R}$ & & 16 & 10 & 10 & 7.76 & 1242 & 0.000 & 0.000 \\
\hline Putamen & $\mathrm{L}$ & & -26 & -4 & 2 & 7.17 & & & 0.000 \\
\hline Putamen & $\mathrm{R}$ & & 30 & -4 & 2 & 5.60 & & & 0.001 \\
\hline Putamen & $\mathrm{R}$ & & 26 & 4 & 0 & 5.32 & & & 0.005 \\
\hline Cingulate gyrus & $\mathrm{R}$ & 24 & 0 & 38 & -2 & 4.33 & 174 & 0.031 & 0.231 \\
\hline Inferior frontal gyrus & $\mathrm{R}$ & $10-47$ & 44 & 42 & -2 & 4.64 & & & 0.079 \\
\hline Middle frontal gyrus & $\mathrm{R}$ & 10 & 32 & 50 & 8 & 5.56 & 708 & 0.000 & 0.002 \\
\hline Middle frontal gyrus & $\mathrm{R}$ & 11 & 32 & 36 & -14 & 4.72 & & & 0.060 \\
\hline Middle frontal gyrus & $\mathrm{L}$ & 10 & -28 & 46 & 10 & 5.19 & 509 & 0.000 & 0.009 \\
\hline Middle frontal gyrus & $\mathrm{L}$ & $10-46$ & -32 & 38 & 20 & 4.49 & & & 0.172 \\
\hline Middle frontal gyrus & $\mathrm{R}$ & 44 & 52 & 14 & 10 & 5.34 & 513 & 0.000 & 0.004 \\
\hline Middle frontal gyrus & $\mathrm{R}$ & 6 & 32 & 8 & 46 & 4.18 & & & 0.366 \\
\hline Middle frontal gyrus & $\mathrm{L}$ & 11 & -30 & 38 & -12 & 4.7 & 154 & 0.046 & 0.064 \\
\hline Superior frontal gyrus & $\mathrm{L}$ & 11 & -10 & 52 & -24 & 3.87 & 77 & 0.251 & 0.710 \\
\hline Superior frontal gyrus & $\mathrm{R}$ & 11 & 16 & 64 & -20 & 3.84 & 39 & 0.590 & 0.746 \\
\hline Superior frontal gyrus & $\mathrm{R}$ & 6 & 20 & -6 & 60 & 3.62 & 35 & 0.640 & 0.925 \\
\hline Precentral gyrus & $\mathrm{R}$ & 6 & 54 & 4 & 10 & 4.71 & & & 0.061 \\
\hline Precentral gyrus & $\mathrm{R}$ & 4 & 46 & -14 & 38 & 4.94 & 512 & 0.000 & 0.024 \\
\hline Postcentral gyrus & $\mathrm{R}$ & 40 & 56 & -18 & 14 & 4.39 & & & 0.195 \\
\hline Postcentral gyrus & $\mathrm{L}$ & $1-2$ & -38 & -26 & 40 & 3.76 & 20 & 0.835 & 0.821 \\
\hline Inferior parietal lobule & $\mathrm{R}$ & 40 & 40 & -38 & 46 & 3.70 & & & 0.879 \\
\hline
\end{tabular}

$\mathrm{BA}=$ Brodmann area; $x, y, z=$ coordinates of peaks in Talairach's system; $\mathrm{L}=$ left; $\mathrm{R}=$ right; $n=8$ for HD patients; $n=$ 17 for healthy controls. Significant $\mathrm{P}<0.0005$, uncorrected (Corrected values are also in the table) 
Table 6

Negative correlational relationships between metabolism and scores on the script generation and script for the HD patients

\begin{tabular}{|c|c|c|c|c|c|c|c|}
\hline \multirow{2}{*}{$\begin{array}{l}\text { Cognitive domain } \\
\text { Anatomical region }\end{array}$} & \multirow[t]{2}{*}{ Side } & \multirow[t]{2}{*}{ BA } & \multicolumn{3}{|c|}{ Talairach coordinates } & \multirow[t]{2}{*}{ Z-score } & \multirow{2}{*}{$\begin{array}{l}\text { Number of } \\
\text { voxels }\end{array}$} \\
\hline & & & $\mathrm{x}$ & $\mathrm{y}$ & $\mathrm{z}$ & & \\
\hline \multicolumn{8}{|c|}{ Sequencing errors (Script generation) } \\
\hline Inferior frontal gyrus & $\mathrm{L}$ & $46 / 45$ & -42 & 26 & 22 & 3.29 & 34 \\
\hline Inferior frontal gyrus & $\mathrm{R}$ & $46 / 45$ & 38 & 28 & 22 & 3.10 & 22 \\
\hline Middle temporal gyrus & $\mathrm{R}$ & 21 & 50 & 2 & -16 & 3.70 & 154 \\
\hline Precentral gyrus & $\mathrm{L}$ & 6 & -40 & 0 & 34 & 3.35 & 55 \\
\hline \multicolumn{8}{|c|}{ Boundary errors (Script generation) } \\
\hline Middle frontal gyrus & $\mathrm{R}$ & 10 & 12 & 64 & 22 & 3.19 & 36 \\
\hline Middle frontal gyrus & $\mathrm{L}$ & 10 & -40 & 50 & 22 & 3.50 & 22 \\
\hline Superior frontal gyrus & $\mathrm{R}$ & 6 & 20 & -8 & 72 & 4.57 & 49 \\
\hline Superior frontal gyrus & $\mathrm{R}$ & 9 & 24 & 62 & 26 & 4.00 & 34 \\
\hline Superior frontal gyrus & $\mathrm{R}$ & 6 & 12 & 6 & 58 & 3.39 & 74 \\
\hline Superior frontal gyrus & $\mathrm{R}$ & 6 & 10 & -4 & 64 & 3.32 & \\
\hline Superior temporal gyrus & $\mathrm{L}$ & $28 / 38$ & -16 & 12 & -28 & 3.16 & 20 \\
\hline Superior temporal gyrus & $\mathrm{L}$ & $28 / 38$ & -22 & 8 & -24 & 2.62 & \\
\hline Inferior temporal gyrus & $\mathrm{L}$ & 20 & -42 & -18 & -26 & 3.33 & \\
\hline Precentral gyrus & $\mathrm{L}$ & 4 & -34 & -20 & 70 & 3.36 & 53 \\
\hline Postcentral gyrus & $\mathrm{L}$ & 40 & -64 & -24 & 26 & 4.43 & 37 \\
\hline Inferior parietal gyrus & $\mathrm{L}$ & 40 & -60 & -32 & 24 & 2.59 & \\
\hline Cingulate gyrus & $\mathrm{R}$ & 24 & 10 & 4 & 46 & 2.74 & \\
\hline Cingulate gyrus & $\mathrm{L}$ & 24 & -4 & 14 & 24 & 3.24 & 35 \\
\hline Cingulate gyrus & $\mathrm{L}$ & 24 & -14 & 14 & 28 & 2.95 & \\
\hline Cingulate gyrus & $\mathrm{L}$ & 32 & -10 & 30 & -10 & 3.48 & 88 \\
\hline Hippocampal gyrus & $\mathrm{R}$ & & 32 & -12 & -16 & 4.42 & 73 \\
\hline Hippocampal gyrus & $\mathrm{L}$ & $20 / 38$ & -26 & -18 & -36 & 3.68 & 256 \\
\hline \multirow[t]{2}{*}{ Hippocampal gyrus } & $\mathrm{L}$ & 35 & -16 & -8 & -22 & 3.46 & 111 \\
\hline & & & -36 & -18 & -14 & 3.69 & \\
\hline Substancia nigra & & & -10 & -12 & -6 & 3.41 & \\
\hline Pons & & & -10 & -12 & -16 & 3.11 & \\
\hline Pons & & & 4 & -16 & -38 & 3.42 & 165 \\
\hline Pons & & & 2 & -28 & -34 & 3.36 & \\
\hline \multirow[t]{2}{*}{ Pons } & & & -2 & -28 & -24 & 2.86 & \\
\hline & & & 38 & 48 & -20 & 3,31 & 28 \\
\hline \multicolumn{8}{|c|}{ Perseverative errors (Script generation) } \\
\hline Superior frontal gyrus & $\mathrm{R}$ & 6 & 10 & -4 & 78 & 3.44 & 74 \\
\hline Superior frontal gyrus & $\mathrm{R}$ & 6 & -2 & -8 & 76 & 2.61 & \\
\hline Inferior frontal gyrus & $\mathrm{L}$ & $44 / 45$ & -42 & 18 & 18 & 3.76 & 44 \\
\hline Postcentral gyrus & $\mathrm{L}$ & $1 / 2$ & -40 & -32 & 58 & 3.30 & 36 \\
\hline Cingulate gyrus & $\mathrm{R}$ & 24 & 16 & -2 & 44 & 3.44 & 43 \\
\hline \multicolumn{8}{|c|}{ Relevant intrusion (Script generation) } \\
\hline \multirow[t]{2}{*}{ Superior frontal gyrus } & $\mathrm{L}$ & 6 & -14 & 0 & 76 & 4.19 & 483 \\
\hline & & 7 & 14 & -54 & 76 & 3.82 & \\
\hline Superior frontal gyrus & $\mathrm{L}$ & 6 & -4 & 6 & 76 & 3.75 & \\
\hline Middle frontal gyrus & $\mathrm{L}$ & 11 & -38 & 32 & -16 & 3.21 & 27 \\
\hline \multirow[t]{2}{*}{ Middle temporal gyrus } & $\mathrm{R}$ & 21 & 72 & -12 & -12 & 3.2 & 40 \\
\hline & & & 74 & -24 & -12 & 2.97 & \\
\hline
\end{tabular}


Middle temporal gyrus

Cingulate gyrus

$21 \quad 64 \quad-48$

2.9

20

Cingulate gyrus /precuneus

$30 / 23$

$\begin{array}{ll}04 & -48 \\ 0 & -54\end{array}$

$$
-4
$$

3.58

Fusiform gyrus

$23 / 31$

$0 \quad-56$

20

4.87

152

Lingual gyrus

$\begin{array}{llll}\mathrm{R} & 37 & 44 & -50\end{array}$

$-16$

3.72

55

Precuneus

L 17

$-88$

$-14$

4

78

L 7

$-6 \quad-66$

62

3.75

92

Precuneus

$\begin{array}{llllll}19 & 38 & -84 & 16 & 3.58 & 79\end{array}$

$\mathrm{R}$

19

20

$-86$

3.47

55

Cuneus

L $\quad 18$

$\begin{array}{lll}12 & -86 & 38\end{array}$

3.06

3.96

85

Cuneus

Middle occipital gyus

R 18

$-100 \quad 8$

3.33

$-24$

$-96-2$

3.38

100

Cerebellum

R 18

$-100$

3.35

$\begin{array}{lll}24 & -94 & 22\end{array}$

2.95

Sequencing errors (Script sorting)

Middle frontal gyrus

Inferior frontal gyrus

Middle temporal gyrus

Superior parietal lobule

$\mathrm{R}$

$18 \quad-98 \quad 14$

2.99

Inferior parietal gyrus

Inferior parietal lobule

$42 \quad-60 \quad-20$

Postcentral gyrus

Postcentral gyrus

$\begin{array}{ccccccc}\mathrm{L} & 46 & -44 & 26 & 26 & 3.28 & 39 \\ \mathrm{R} & 46 / 45 & 42 & 30 & 14 & 3.78 & 83 \\ \mathrm{R} & 21 & 62 & 0 & -20 & 3.43 & 30 \\ \mathrm{R} & 7 & 36 & -56 & 48 & 2.79 & \\ \mathrm{R} & 40 & 44 & -56 & 44 & 3.60 & 53 \\ \mathrm{R} & 40 & 52 & -62 & 38 & 2.88 & \\ \mathrm{R} & 2 & 28 & -34 & 58 & 3.33 & 24 \\ \mathrm{R} & 2 & 20 & -38 & 56 & 2.73 & \\ \mathrm{R} & 17 & 4 & -80 & 6 & 4.35 & 266 \\ \mathrm{~L} & 17 / 18 & -4 & -88 & -2 & 3.40 & \\ \mathrm{R} & 17 / 18 & 16 & -96 & 4 & 2.84 & 23 \\ \mathrm{R} & 37 & 32 & -50 & -12 & 3.62 & 25 \\ \mathrm{R} & 19 & 24 & -76 & -14 & 3.56 & 72 \\ \mathrm{~L} & 18 & -16 & -82 & -18 & 3.25 & 32 \\ \mathrm{~L} & & -24 & -56 & -16 & 3.14 & 31\end{array}$

Cuneus

Cuneus

Cuneus

Fusiform gyrus

Fusiform gyrus

Lingual gyrus

L

$\begin{array}{lll}-24 & -56 & -16\end{array}$

3.14

39

83

30

53

24

266

23

25

72

32

The table shows regions in which there was a significant negative correlation between metabolism and scores on the script generation and script sorting. All voxels are significant at a threshold of $\mathrm{P}<0.005$, uncorrected for multiple comparisons across the whole brain volume. 


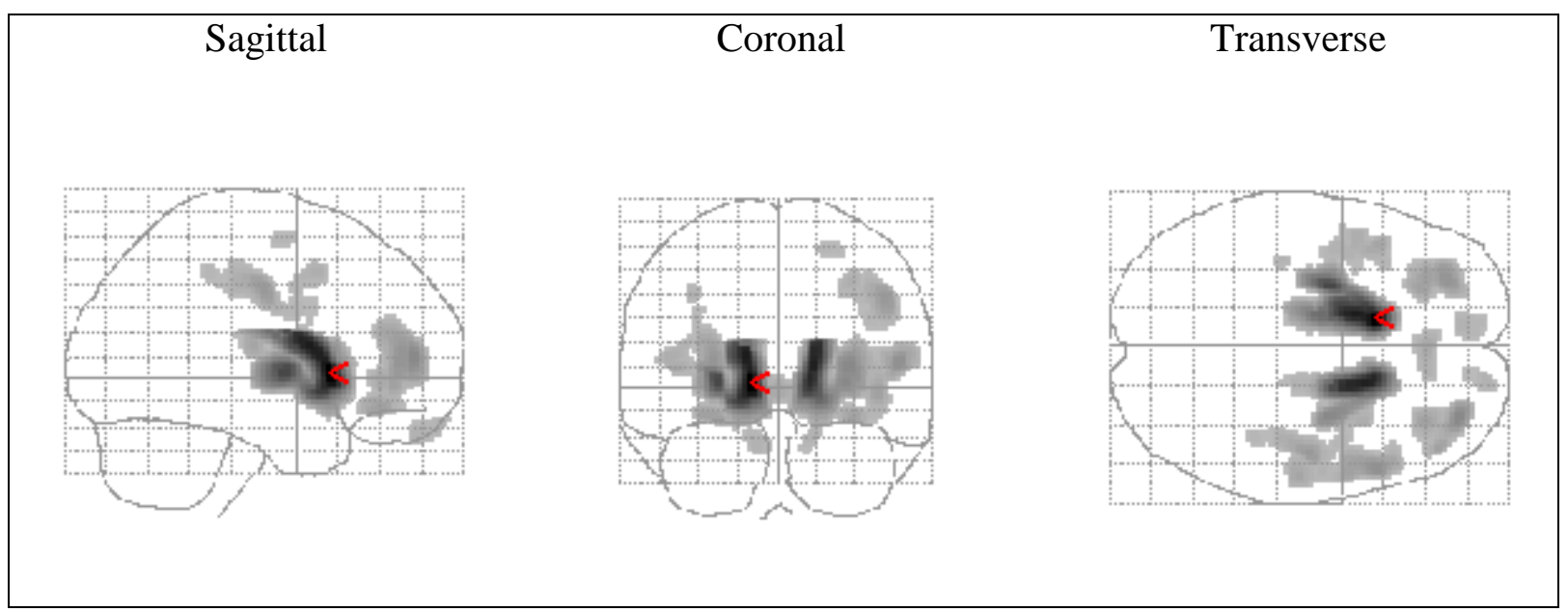

Fig. 1. Glassview of the t-test statistical $t$-map thresholded at $\mathrm{P}<0.0005$, uncorrected. 
Research highlights

The correlation between resting-state brain glucose utilization and performance on script generation and sorting tasks was examined in Huntington's disease.

A selectively greater impairment for the organizational aspects of scripts was observed.

Significant negative correlations between script errors and the metabolism of several cortical frontal and posterior regions were found.

The cortical frontal regions are more crucial in script retrieval and script sequencing than the basal ganglia. 